\title{
New Equivalent Linear Impact Model for Simulation of Seismic Isolated Structure Pounding against Moat Wall
}

\author{
Yang Liu, ${ }^{1}$ Wen-Guang Liu, ${ }^{1}$ Xin Wang, ${ }^{2}$ Wen-Fu He, ${ }^{1}$ and Qiao-Rong Yang ${ }^{1}$ \\ ${ }^{1}$ Department of Civil Engineering, Shanghai University, Shanghai 200072, China \\ ${ }^{2}$ School of Mechanicals, Shanghai Dianji University, 1350 Ganlan Road, Shanghai, China \\ Correspondence should be addressed to Wen-Guang Liu; liuwg@aliyun.com
}

Received 4 July 2014; Accepted 18 September 2014; Published 24 November 2014

Academic Editor: Dumitru I. Caruntu

Copyright (c) 2014 Yang Liu et al. This is an open access article distributed under the Creative Commons Attribution License, which permits unrestricted use, distribution, and reproduction in any medium, provided the original work is properly cited.

\begin{abstract}
Base-isolated buildings subjected to extreme earthquakes or near-fault pulse-like earthquakes can exceed their design gap distance and impact against the surrounding moat wall. Based on equating energy dissipation and maximum collision compression deformation of isolated structure with the Hertz-damp model and Kevin-Voigt model in the process of collision, an equivalent linear impact model (ELIM) is proposed to better predict impact response of seismic isolated structure. The formula of the equivalent linear stiffness of ELIM is theoretically derived. The effectiveness of ELIM is verified by comparing the results of numerical analyses with the results of pounding experiments. Four near-fault earthquakes are selected to validate rationality and accuracy of the proposed model using numerical analysis. The results indicate that the proposed linear model can nearly capture impact behavior of isolated structure in simulating the pounding-involved structural response.
\end{abstract}

\section{Introduction}

Base-isolated structure can be subjected to impact with surrounding retaining walls during strong earthquake shaking containing low-frequency energy if there is insufficient clearance between these elements. It may be the major cause of seismic damage or even collapse of the buildings during earthquakes. In the February 2011 Christchurch earthquake, $6 \sim 12 \%$ of the surveyed buildings were observed to have severe damage resulting from pounding [1].

Impact problem of a base-isolated structure has gained the interest of researchers. Nagarajaiah and Sun studied a base-isolated fire command and control building in Los Angeles during 1994 Northridge earthquake. It was observed that the response of base-isolated buildings has been altered significantly due to the occurrence of impact [2]. Matsagar and Jangid examined the case of seismically isolated multidegree-of-freedom (MDOF) structures pounding with various types of isolation systems using Newmark's step-bystep iteration method [3]. They also investigated the seismic response of a single-story asymmetric structure supported on various base isolation systems during the impact with adjacent structures [4]. Through parametric analyses, Komodromos et al. investigated the pounding effects of a seismically isolated building with the surrounding moat wall, which revealed the detrimental effects of the structural impacting on the effectiveness of seismic isolation $[5,6]$. Agarwal et al. examined the case of a seismically isolated building pounding with an adjacent fixed-supported building [7]. Polycarpou and Komodromos investigated the effects of potential pounding incidences on the seismic response of a typical seismically isolated building subjected to various earthquake excitations by numerical simulations $[8,9]$. Pant and Wijeyewickrema studied seismic pounding of a typical four-story base-isolated reinforced concrete (RC) building with retaining walls at the base and a four-story fixed-base RC building using three-dimensional finite element analyses [10]. Masroor and Mosqueda conducted a series of earthquake simulation experiments to assess the performance of ultimate state of seismically isolated buildings under strong ground motions including pounding against a moat wall [11]. Moustafa and Mahmoud assessed the pounding of 
adjacent buildings with fixed-base and isolated-base using input energy, dissipated energy, and damage indices [12]. Previous studies indicated that the responses of base-isolated buildings were substantially influenced by seismic pounding.

Engineering structural pounding is a complex phenomenon involving plastic deformations at contact points, local cracking or crushing, fracturing due to impact, friction, and so forth. There are generally two different approaches to model structural pounding [14]. The first one applies the classical theory of impact, stereomechanics, which is based on the laws of conservation of energy and momentum and does not consider transient stresses and deformations in the impacting bodies [15-17]. The second approach to model pounding is to directly simulate the pounding force during impact. The pounding force between colliding structures is usually modeled by elastic or viscoelastic impact elements which become active when the contact is detected. Most proposed elements represent local force penetration of two objects at the contact point without considering the vibration aspect of collision. Typical models are linear spring-damper (KelvinVoigt) models for viscoelastic behavior [10] and nonlinear spring elements based on Hertz contact law $[17,18]$. Related to this work, Komodromos et al. [5] investigated the use of common force-based impact models to simulate pounding of concrete slabs in isolated buildings to moat walls, including a linear viscoelastic model with permanent deformation to avoid tensile impact forces during restitution. Polycarpou et al. [19] proposed a new nonlinear inelastic force-based impact model to describe the behavior of rubber dumpers under impact loading, as an alternative in mitigating the impact force. Pant and Wijeyewickrema [20] developed modified Kelvin-Voigt (MKV) model, which had been extended to simulate pounding with friction of a base-isolated building with retaining walls at the base. Khatiwada et al. [21] proposed a generic model that can have either a linear or nonlinear force-deformation relationship for the analysis of building pounding. $\mathrm{Xu}$ et al. [22] investigated the random response of vibrating system with inelastic impact which is described through a modified Hertzian contact model by an equivalent nonlinearization technique. Abdel Raheem [23] studied the effect of impact using linear and nonlinear contact force model for different separation distances and compared them with nominal model without pounding consideration. Most commercial software packages provide the linear spring element with a gap to model impact, but linear model parameter is hard to determine. For simplification, the total stiffness of the contact elements placed on any side of the base slab is assumed to be equal to the axial stiffness of the slab, but it lacks some theory foundations. Although numerical analysis results using the nonlinear Hertz spring model have a good agreement with experimental results, the nonlinear Hertz spring mode cannot be directly used in the commercial software packages [24]. Muthukumar [13] showed that a bilinear spring can provide a reasonable substitute. However, it is related to a key parameter $a$. Thus, a new linear model whose parameters can be easily determined in practice engineering is urgently needed to study for accuracy simulation of impact behavior.
In this paper, an equivalent linear impact model (ELIM) is proposed to study the behavior of isolated structure pounding with moat wall. Formula of the equivalent linear stiffness of ELIM is theoretically derived, based on equating energy dissipation and maximum collision compression deformation of isolated structure using the Hertz-damp model and KevinVoigt model in the process of collision. Subsequently, the results of numerical simulations have been compared with the results of an impact experiment conducted by dropping balls. Finally, simulation results and sensitivity analyses are presented to check the accuracy of the proposed model which captures the behavior of isolated structure pounding with moat wall.

\section{New Equivalent Linear Impact Model (ELIM)}

Figure 1 shows the model of impact between two colliding bodies. The Hertz-damp model is used in the first impact system, and linear viscoelastic impact model is used in the second impact system. According to stereomechanical model, the energy loss $\Delta E$ during the impact can be expressed in terms of the coefficient of restitution $e$ and the approaching velocities $v_{1}, v_{2}$ of two colliding bodies as follows [25]:

$$
\Delta E=\frac{1}{2} \frac{m_{1} m_{2}}{m_{1}+m_{2}}\left(1-e^{2}\right)\left(v_{1}-v_{2}\right)^{2} .
$$

The Hertz contact law [17] was originally proposed for static contact of two bodies, in which stresses and deformations near the contact point were described as a function of the geometric and elastic properties of the bodies. The contact force is related to the relative indentation of two bodies with a nonlinear spring of stiffness Hertz-damp impact model which can be described as $[25,26]$

$$
\begin{gathered}
F_{c}=k_{h} \delta^{3 / 2}+c_{h} \dot{\delta} ; \quad \delta \geq 0, \\
F_{c}=0 ; \quad \delta<0 .
\end{gathered}
$$

The nonlinear damping coefficient is taken as follows [27]:

$$
c_{h}=\xi_{h} \delta^{3 / 2} .
$$

The contact force is related to the relative indentation of two bodies with a nonlinear spring having a stiffness $k_{h}$ calculated as [26]

$$
\begin{gathered}
k_{h}=\frac{4}{3 \pi}\left(\frac{1}{\lambda_{1}+\lambda_{2}}\right) \sqrt{\frac{R_{1} R_{2}}{R_{1}+R_{2}}}, \\
\lambda_{i}=\frac{1-v_{i}^{2}}{\pi E_{i}}, \\
R_{i}=\sqrt[3]{\frac{3 m_{i}}{4 \pi \rho_{i}}} .
\end{gathered}
$$

The linear viscoelastic impact model, also known as Kelvin-Voigt model, is one of the most commonly used 


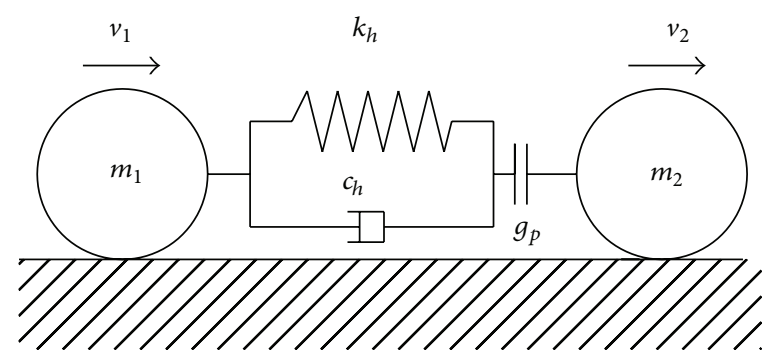

(a)

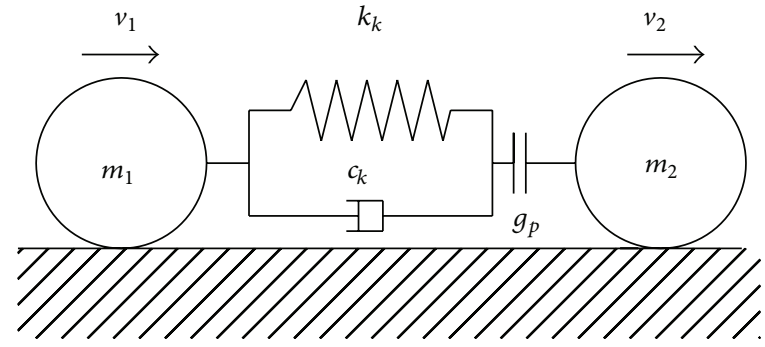

(b)

FIGURE 1: Equivalent model of impact between two colliding bodies: (a) system 1 with Hertz-damp model and (b) system 2 with Kelvin model.

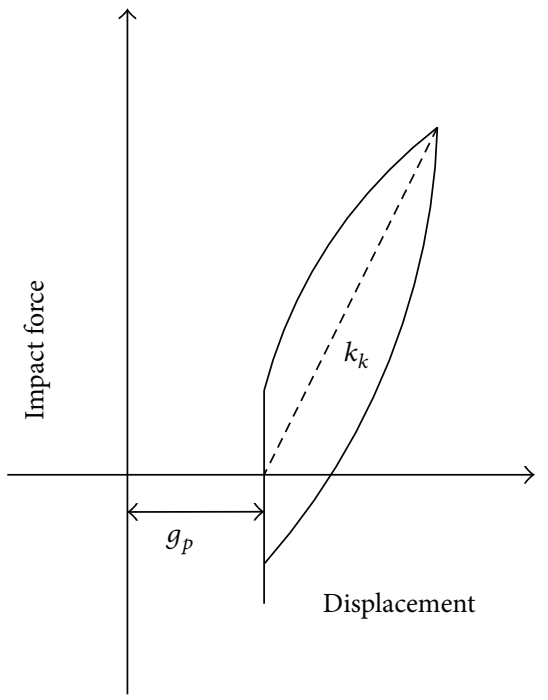

(a)

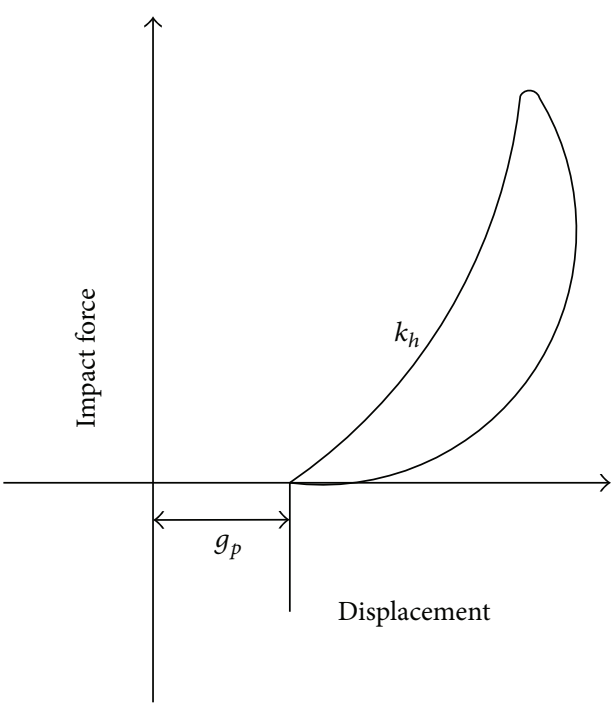

(b)

FIGURE 2: Contact force-displacement relationship for various impact models: (a) Kelvin model and (b) Hertz-damp model [13].

models in structural pounding and consists of a linear impact spring and a viscous impact dashpot. The Hertz-damp model and Kelvin-Voigt model are shown in Figure 2. Owing to its simplicity, the linear viscoelastic model has been widely used for the simulation of structural pounding. The impact force $F_{c}$ is provided by the expression [25]

$$
\begin{gathered}
F_{c}=k_{k} \delta+c_{k} \dot{\delta} ; \quad \delta \geq 0, \\
F_{c}=0 ; \quad \delta<0 .
\end{gathered}
$$

The impact of element damping can be obtained from the formula

$$
c_{k}=\xi_{k} \delta^{n}
$$

The damping ratio is [27]

$$
\xi_{k}=\frac{3 k_{k}(1-e)}{2 e\left(v_{1}-v_{2}\right)} .
$$

Considering the momentum and energy balance between the start and the end of the compression phase, we have

$$
\begin{aligned}
\frac{1}{2} m v_{1}^{2}+\frac{1}{2} m v_{2}^{2}= & \int_{0}^{\delta_{\max }} k_{h} \delta^{n} d \delta+\int_{0}^{\delta_{\max }} \xi_{h} \delta^{n} \dot{\delta} d \delta \\
& +\frac{1}{2}\left(m_{1}+m_{2}\right) V^{2} \\
= & \frac{k_{h} \delta_{\max }^{n+1}}{n+1}+\int_{0}^{\delta_{\max }} \xi_{h} \delta^{n} \dot{\delta} d \delta \\
& +\frac{1}{2}\left(m_{1}+m_{2}\right) V^{2}, \\
m v_{1}+ & m v_{2}=\left(m_{1}+m_{2}\right) V .
\end{aligned}
$$

Substituting (9) into (8) yields

$$
\frac{k_{h} \delta_{\max }^{n+1}}{n+1}+\int_{0}^{\delta_{\max }} \xi_{h} \delta^{n} \dot{\delta} d \delta=\frac{1}{2} \frac{m_{1} m_{2}}{m_{1}+m_{2}}\left(v_{1}-v_{2}\right)^{2} .
$$




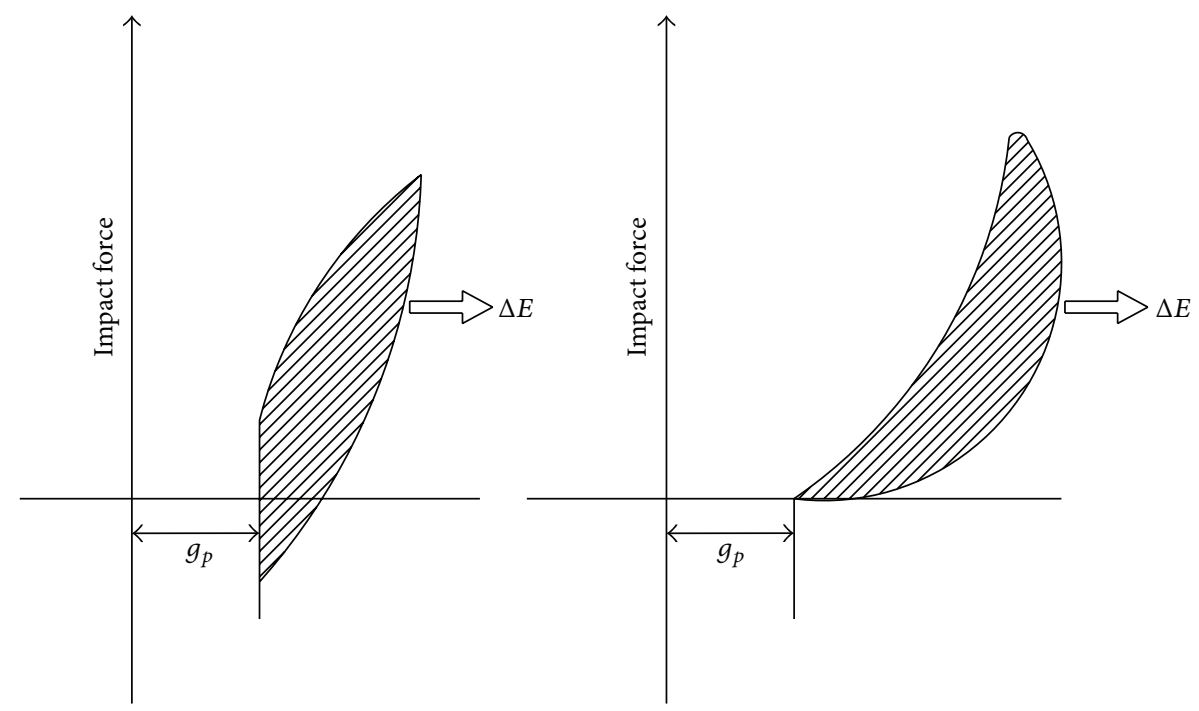

FIGURE 3: Equal energy dissipated for various impact models.

In the equation, the second formula is energy dissipated by the damping force.

The energy dissipated by the damping force can be evaluated as

$$
\Delta E_{1}=\int_{0}^{\delta_{\max }} \xi_{h} \delta^{n} \dot{\delta} d \delta .
$$

The energy dissipated by the damping force in the compression and restitution phase

$$
\begin{gathered}
\Delta E_{2}=e \Delta E_{1}, \\
\Delta E=\Delta E_{1}+\Delta E_{2} .
\end{gathered}
$$

Substituting (13) into (12) yields

$$
\begin{gathered}
\frac{k_{h} \delta_{\max }^{n+1}}{n+1}+\frac{1}{2} \frac{m_{1} m_{2}}{m_{1}+m_{2}}(1-e)\left(v_{1}-v_{2}\right)^{2} \\
=\frac{1}{2} \frac{m_{1} m_{2}}{m_{1}+m_{2}}\left(v_{1}-v_{2}\right)^{2} .
\end{gathered}
$$

This energy loss can be expressed by [28]

$$
\Delta E=\frac{k_{h} \delta_{\max }^{n+1}\left(1-e^{2}\right)}{e(n+1)} .
$$

This energy loss of impact bodies using Kevin-Voigt can be expressed by

$$
\Delta E=\frac{1}{3} \xi_{k}\left(v_{1}-v_{2}\right) \delta_{\max }^{2}(1+e) .
$$

Based on equal energy dissipated by the damping force and maximum of two systems using Kelvin-Voigt model and Hertz-damp model (see Figure 3), impact stiffness of KelvinVoigt model can be obtained from (7), (15), and (16):

$$
k_{k}=\frac{4 k_{h}}{5} \sqrt{\delta_{\max }} .
$$

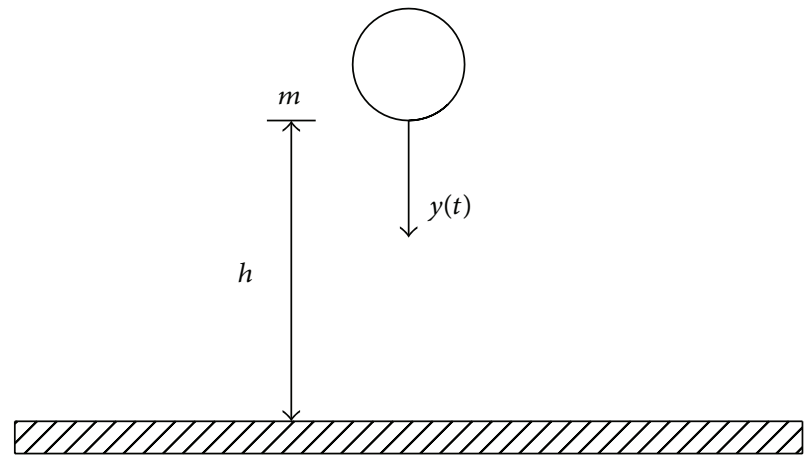

Figure 4: Numerical model of the ball.

\section{Experimental Verification of Pounding Force Models}

In order to verify the accuracy of ELIM of structural pounding, the results of the numerical analysis have been compared with the results of the experiments conducted by Jankowski [29]. It was carried out by dropping balls onto a rigid plane surface of concrete material. In the numerical analysis, the model of pounding between the falling ball and a stationary rigid surface, shown in Figure 4, is used.

The dynamic equation of motion for such a model can be written in the form

$$
m \ddot{y}(t)+f_{p}(t)=m g,
$$

where $m$ is the mass of a ball, $y(t)$ is its vertical acceleration, $g$ stands for the acceleration of gravity, and $f_{p}(t)$ is the pounding force which is equal to zero when $y(t) \leq h$ ( $h$ is a drop height) and can be calculated by (5) when $y(t)>h$, where deformation is $\delta(t)$ expressed as

$$
\delta(t)=y(t)-h .
$$




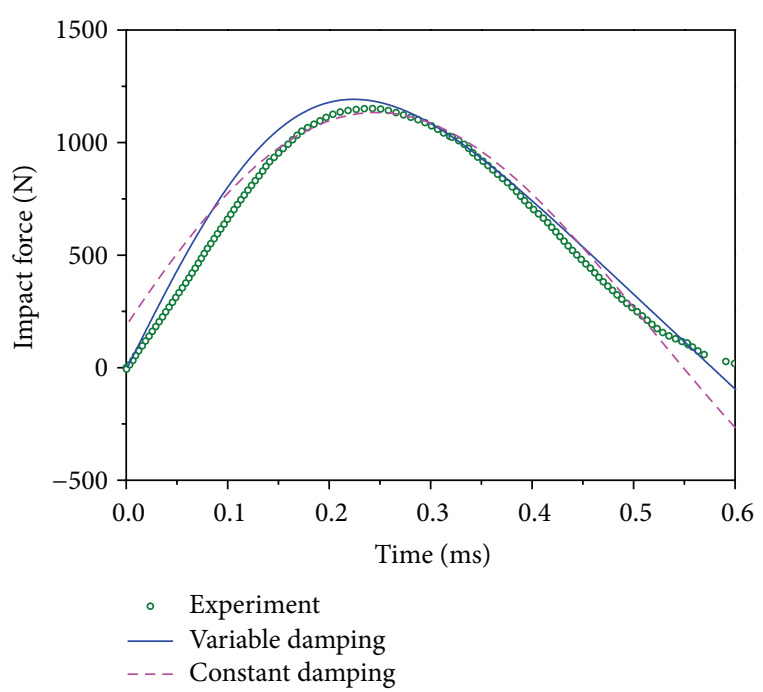

FIGURE 5: Comparison of pounding force time histories between numerical results and experimental results.

TABLE 1: Comparison of impact forces and deformations of pounding model with and without damping.

\begin{tabular}{lcc}
\hline Case & Peak impact force $(\mathrm{N})$ & Peak displacement $(\mathrm{mm})$ \\
\hline With damping & 1192 & $2.17 \times 10^{-2}$ \\
Without damping & 1315 & $2.38 \times 10^{-2}$ \\
\hline
\end{tabular}

A time-stepping integration procedure with constant time step $t=1 \times 10^{-7} \mathrm{~s}$ has been applied to solve the equation of motion (18) numerically. Using (17), the stiffness values of ELIM have been calculated. The pounding force time history measured during the experiment and the histories received from the numerical analysis for the first impact are presented in Figure 5. Figure 5 also compares calculation results with constant damping coefficient and variable damping coefficient. It indicates that there is a good agreement between the numerical and experimental results. In addition, it is found that the physical characteristics of numerical results by using constant damping coefficient are inconsistent with experimental results. This is because in the case of the linear viscoelastic model, the negative force can be observed just before separation. However, maximum impact force obtained from numerical analysis using constant damping coefficient is close to the experimental result.

In practice, some commercial software packages provide the linear spring element with a gap to model impact but cannot give the damping coefficient of impact model. Furthermore, it is complex for engineers to calculate the damping coefficient using (5). Thus, the accuracy of results using ELIM with no damping should be assessed by comparative analysis. Table 1 shows the maximum impact force and deformation of equivalent linear impact model with and without damping. It shows that, regardless of the damping effect, the impact force and impact compression deformation are obviously larger

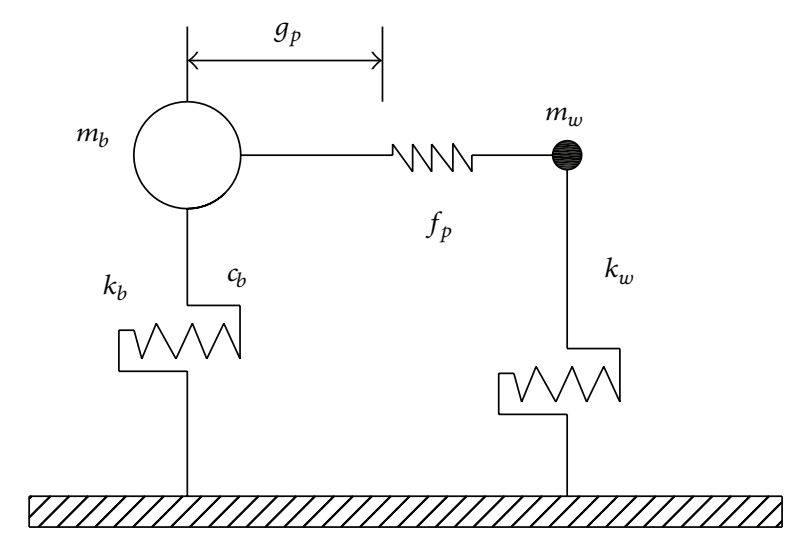

FIGURE 6: Simplified truss contact element of base-isolated structure for impact simulation.

than calculation results considering the damping effect, but the simulation errors are within $30 \%$. The damping effect can reduce the overall vibration response of the structure, so ignoring the effect of damping coefficient cannot lead to unsafe results for performance evaluation of the structure.

\section{Selection of Near-Fault Pulse-Like Ground Motion Records}

Code for seismic design of buildings has prescribed general guidelines but they do not provide specifics for selecting the type of earthquake records for nonlinear dynamic analysis (Katsanos, 2006). In general, it is better to choose the records based on real records which are from strong motions database to consider statistical characteristics of strong motions. Currently, the key ground motions for assembling the database are from the Japanese K-Net strong motion network (NIED), PEER/NGA, and CESMD (http://www.strongmotioncenter .org/). Because of large isolator displacements due to long period pulses associated with the near-fault motion, four different earthquake records (Table 2) are used in order to examine the effects of the characteristics of the excitation on the seismic response of the seismically isolated building during poundings using the proposed model.

All selected large pulse-like earthquake records are characterized by low-frequency content, in order to induce large displacements of the seismically isolated building. These motions cover a moment magnitude range from 6.0 to 7.6 and a rupture distance (closest distance from site to fault rupture plane) range from 0 to $10 \mathrm{~km}$. The peak ground velocities of 4 ground motion records are more than $30 \mathrm{~cm} / \mathrm{s}$. The peak accelerations (PGA) corresponding to earthquakes of major levels are specified to be $0.4 \mathrm{~g}$.

\section{The Simplified Base-Isolated Structure and Moat Wall Model}

The seismic response of a base-isolated structure during impact with the surrounding moat wall is investigated. The 
TABLE 2: Near-fault pulse-like record data.

\begin{tabular}{lccccc}
\hline Number & Event & $R_{\text {rup }}$ & Mechanism & $v_{30}$ & $T_{p}$ \\
\hline N1 & EL CENTRO ARRAY \#10 & 4.0 & Strike-slip & 205.6 & 4 \\
N2 & EL CENTRO ARRAY \#6 & 0.6 & Strike-slip & 210.5 & $4.2,4.5$ \\
N3 & 459 & 6.3 & Strike-slip & 545.0 & $0.86,1.8$ \\
N4 & 802 & 7.0 & Reverse & 513.7 & 4.9 \\
\hline
\end{tabular}
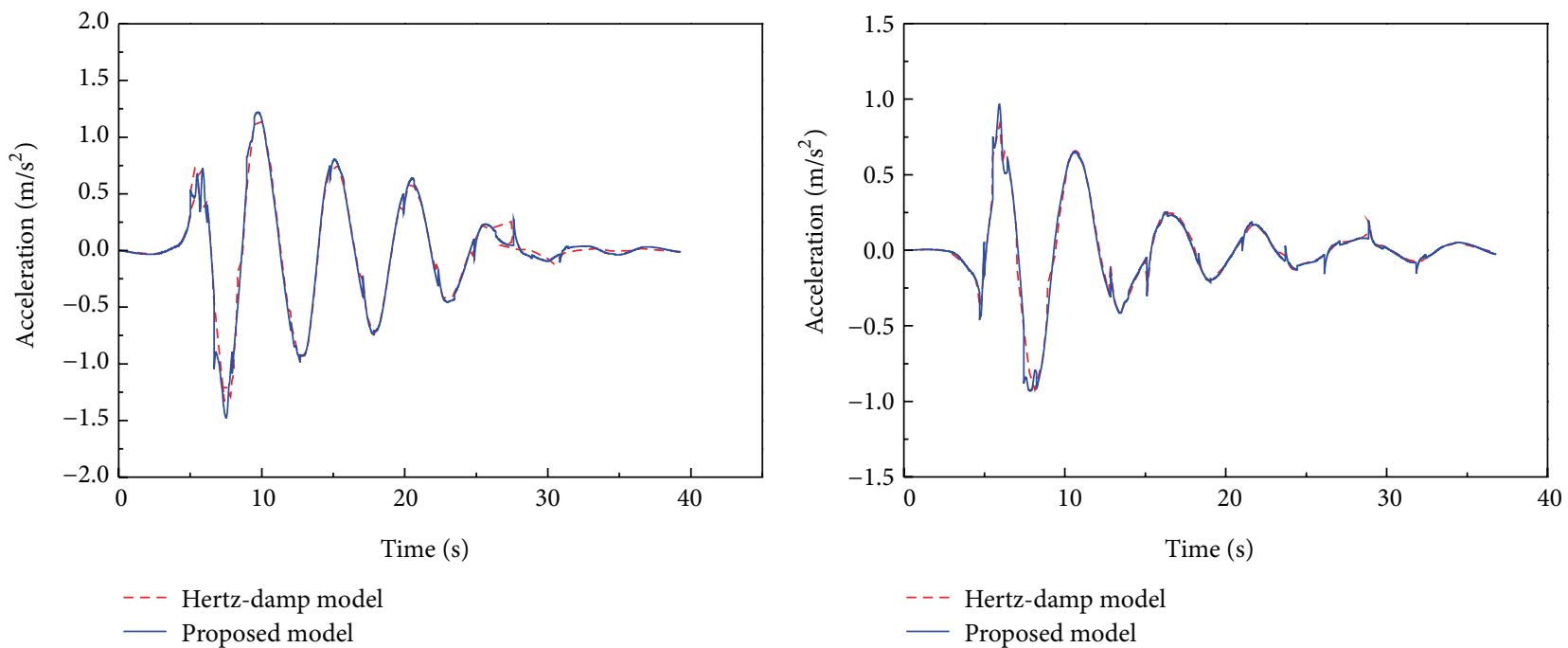

(a)

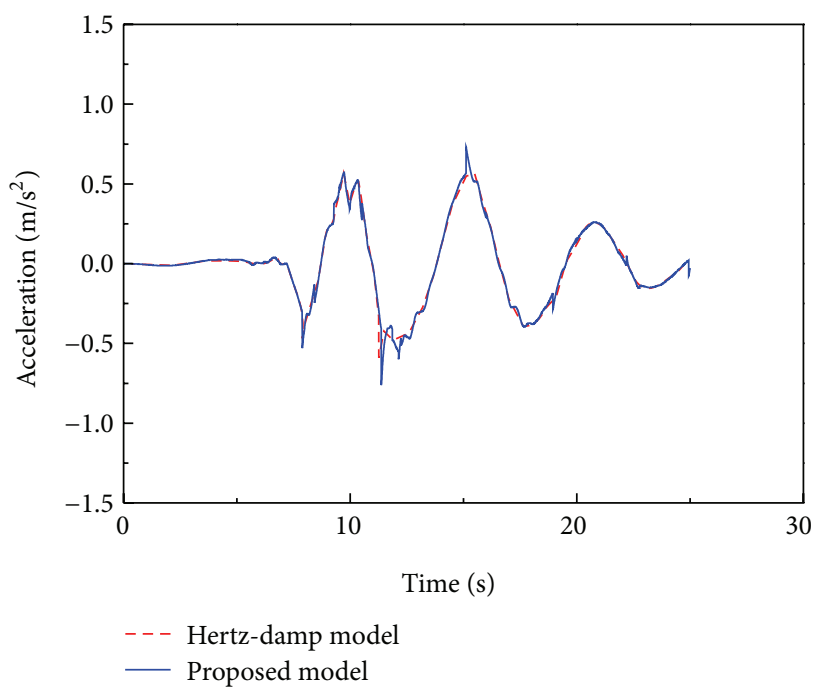

(c)

(b)

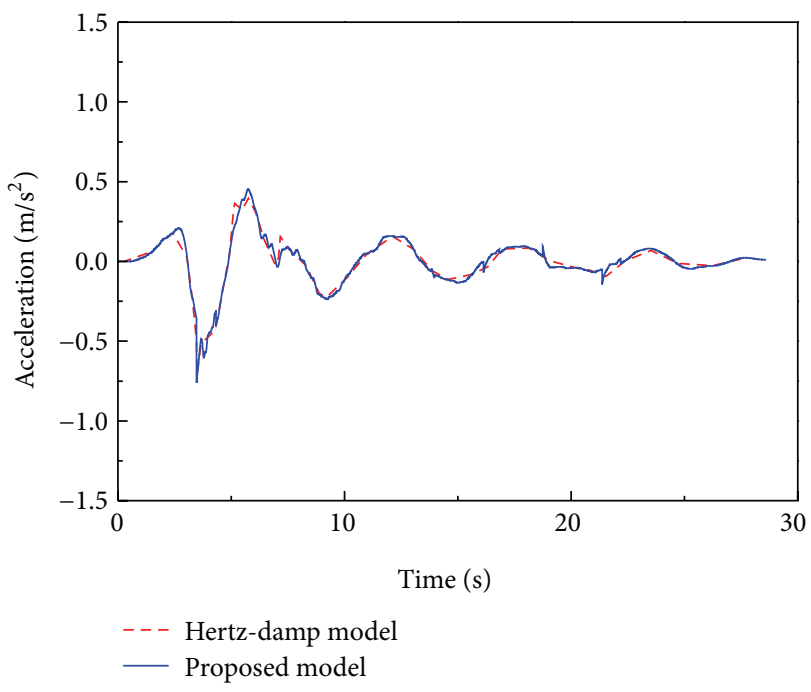

(d)

FIGURE 7: Acceleration time history of isolated structure (a) N1; (b) N2; (c) N3; (d) N4.

numerical studies are carried out using a mathematical model of the base-isolated structure to calculate the response of interest such as the peak absolute acceleration and the peak relative displacement of the isolation layer. The total weight is $200 \mathrm{t}$. The period of base-isolation structure is $3 \mathrm{~s}$. Hertz impact stiffness equals $4.15 \times 10^{6} \mathrm{~N} / \mathrm{m}^{3 / 2}$. The equivalent damping ratio of isolated structure is $10 \%$. Simplified 2 DOF model of base-isolated structure pounding against moat wall is shown in Figure 6. In Figure 6, $x_{b}$ is displacement of isolated structure, $x_{w}$ is displacement of moat wall, and the dynamic equations are

$$
\begin{gathered}
m_{b} \ddot{x}_{b}+k_{b} x_{b}+c_{b} \dot{x}_{b}+f_{p}(t)=-m_{b} \ddot{x}_{g}, \\
m_{w} \ddot{x}_{w}+k_{w} x_{w}-f_{p}(t)=0
\end{gathered}
$$

where $\ddot{x}_{g}$ is seismic acceleration; $m_{b}, k_{b}$, and $c_{b}$ are mass, stiffness, and damping of isolated structure. $k_{w}$ and $c_{w}$ are stiffness and damping of moat wall; $f_{p}(t)$ is impact force. 


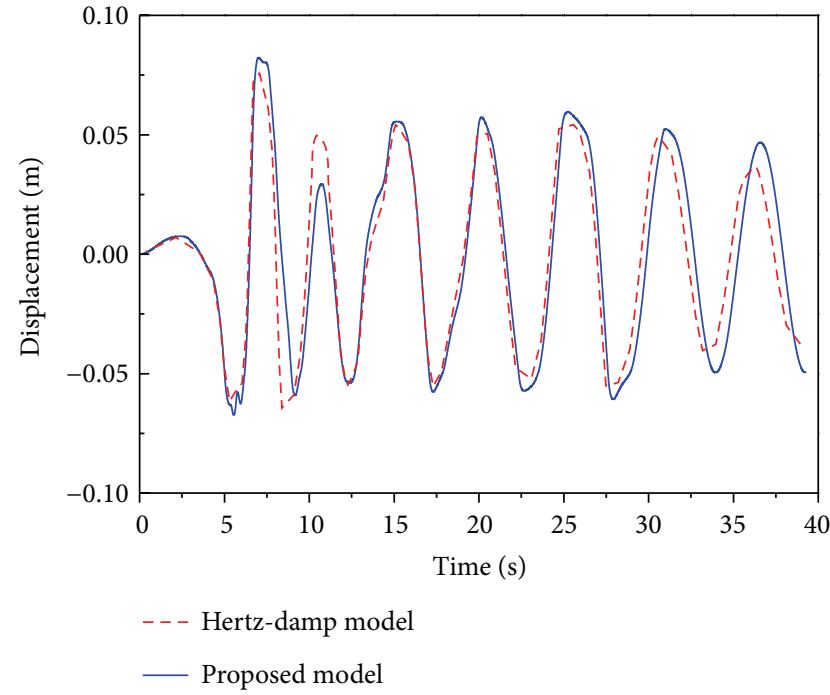

(a)

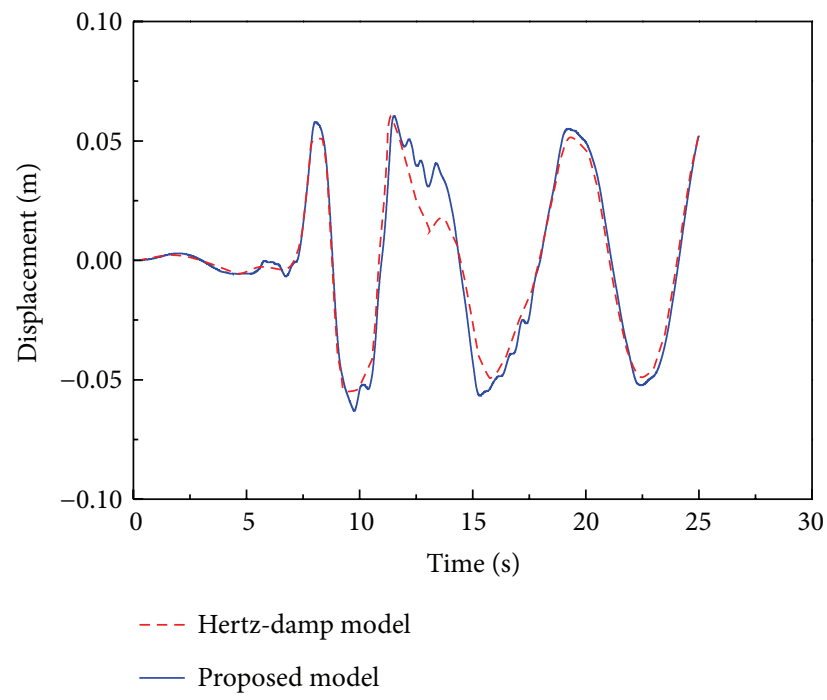

(c)

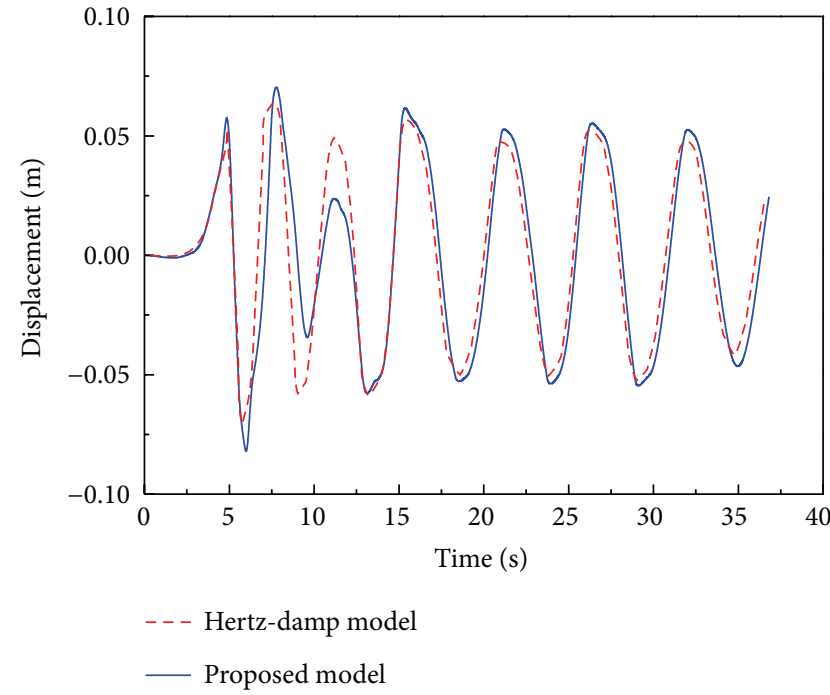

(b)

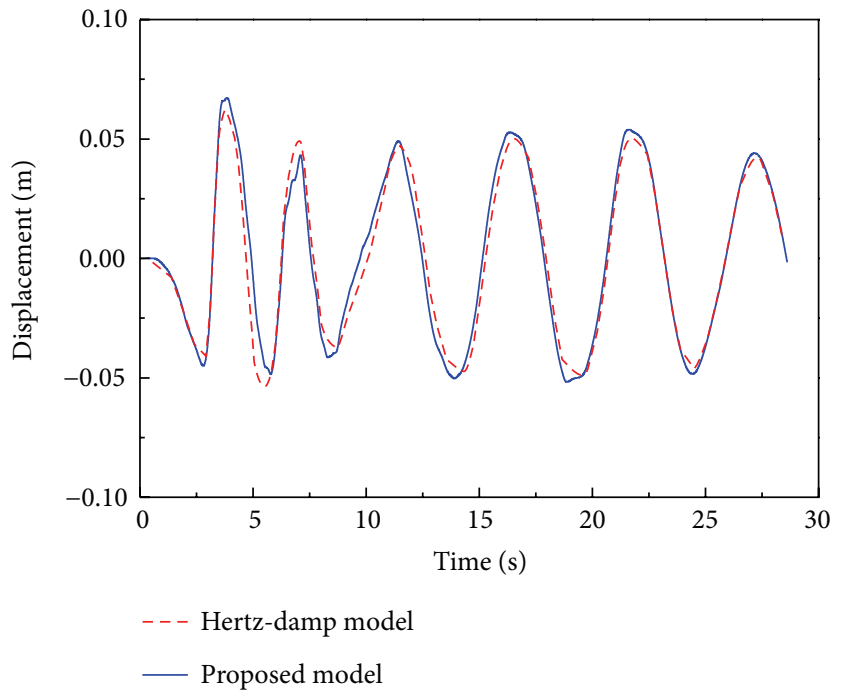

(d)

Figure 8: Displacement time history of isolated structure (a) N1; (b) N2; (c) N3; (d) N4.

\section{Numerical Results}

The numerical procedure has been programmed by MATLAB software. Acceleration, displacement, and impact force of seismically isolated structure are plotted in Figures 7, 8, and 9, respectively. The prediction of acceleration and displacement responses using ELIM is an agreement with the result using Hertz-damp model, and large acceleration responses under four near-fault earthquakes are captured in the numerical model within few errors. By comparing Figures 7 and 9, it can be seen that the maximum values of the acceleration responses of the isolated structure were amplified when impact occurred. The acceleration response for $\mathrm{N} 1$ is $0.14 \mathrm{~g}$, and corresponding impact force is $140.2 \mathrm{kN}$. Although the impact at some points under N4 cannot be well predicted, numerical simulations using ELIM capture the dominant characteristics of the contact force, indicating that the effect of the impact on isolated structure response is largely depending on the earthquake characteristics. The numerical model including ELIM can reproduce the seismic response of baseisolated structure impacting against a moat wall.

\section{Sensitivity Analysis}

Sensitivity analyses were conducted to examine the effects of model parameters on the simulated structural peak responses. The Hertz stiffness $\left(k_{h}\right)$, moat wall spring stiffness $\left(k_{w}\right)$, and isolation layer spring stiffness $\left(k_{b}\right)$ are considered here. Changes in these three parameters over a range of $-50 \%$, $+50 \%$ of their base value were examined for resulting peak 


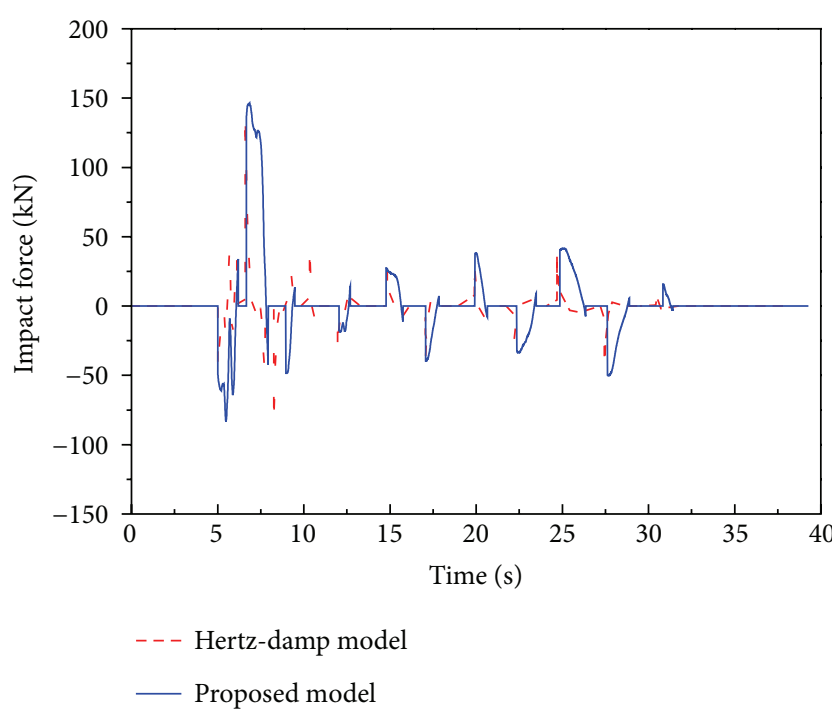

(a)

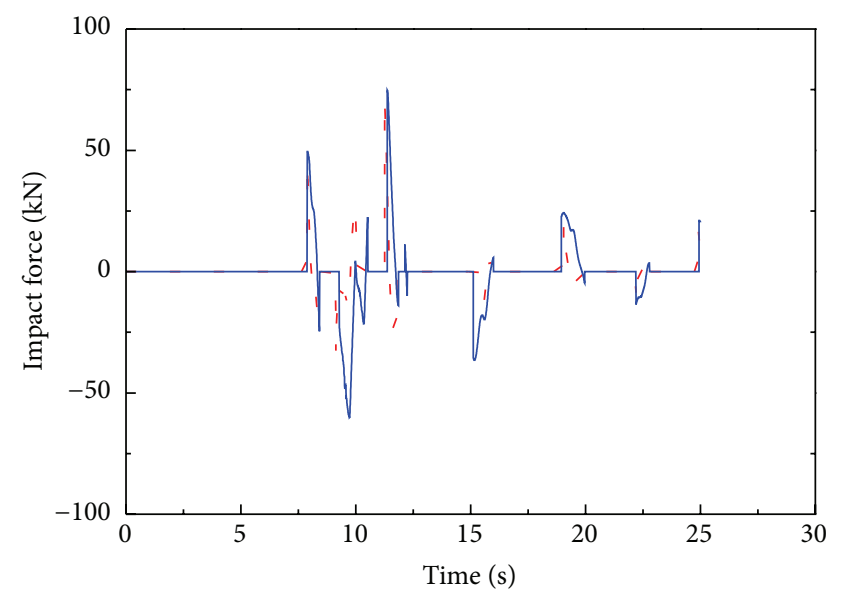

- - - Hertz-damp model

— Proposed model

(c)

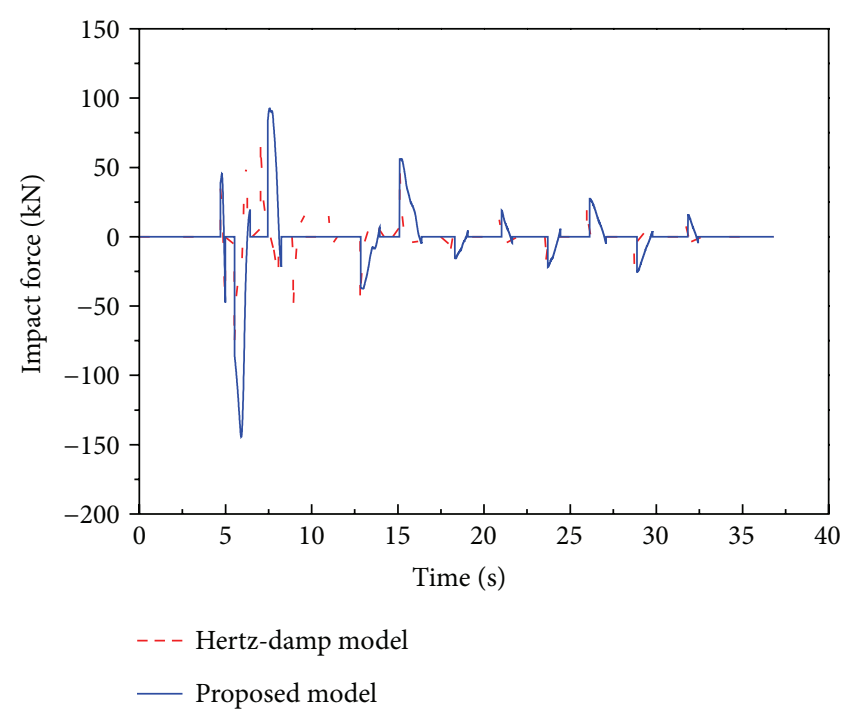

(b)

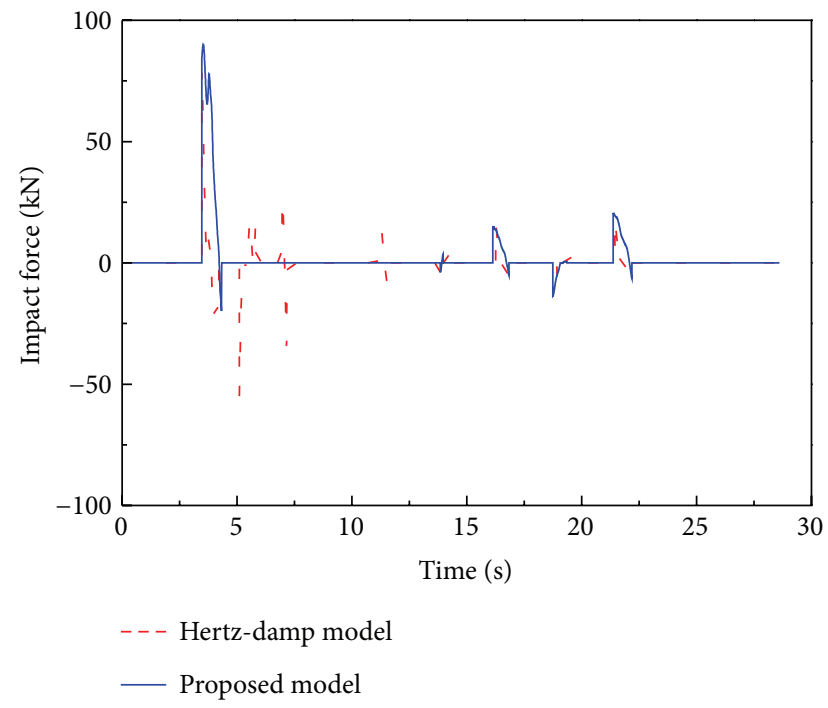

(d)

FIGURE 9: Impact force time history (a) N1; (b) N2; (c) N3; (d) N4.

response of the structure. Ratios between peak responses using ELIM and Hertz model are

$$
\begin{gathered}
\text { Ratio }_{\mathrm{acc}}=\frac{A_{k}-A_{h}}{A_{h}} \times 100 \%, \\
\text { Ratio }_{\text {dis }}=\frac{d_{k}-d_{h}}{d_{h}} \times 100 \%, \\
\text { Ratio }_{f}=\frac{f_{k}-f_{h}}{f_{h}} \times 100 \%,
\end{gathered}
$$

where $A_{h}, d_{h}$, and $f_{h}$ are peak absolute acceleration, displacement, and impact force responses of the isolated structure using Hertz-damp model, respectively; $A_{k}, d_{k}$, and $f_{k}$ are peak absolute acceleration, displacement, and impact force responses of the isolated structure using ELIM, respectively.
Each separate parameter was varied one at a time, and the response of the structure was compared with corresponding results using base values. The base values are obtained from the procedure explained in Section 6 of this paper. Figures 10, 11 , and 12 show the sensitivity of the three parameters on the base level peak acceleration and displacement, respectively. It can be seen that moat wall spring stiffness parameter has the largest effect on impact force of the isolated structure resulting in a maximum $16 \%$ response change in comparison with base values for a $50 \%$ change in model parameter values. Changes in all responses are very small because of changes in Hertz stiffness and moat wall spring stiffness parameters. Figure 12 shows that the isolated structure spring stiffness has the largest effect on the impact force. Impact force obtained using ELIM is underestimated for a $50 \%$ change in spring stiffness of isolated structure, so accurately calculating impact 


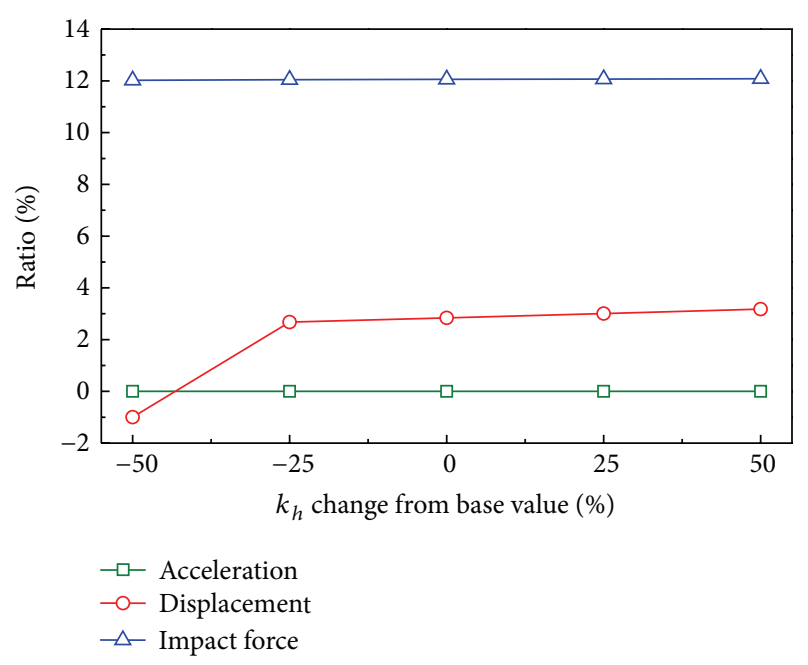

Figure 10: Effect of changing Hertz stiffness on structural response.

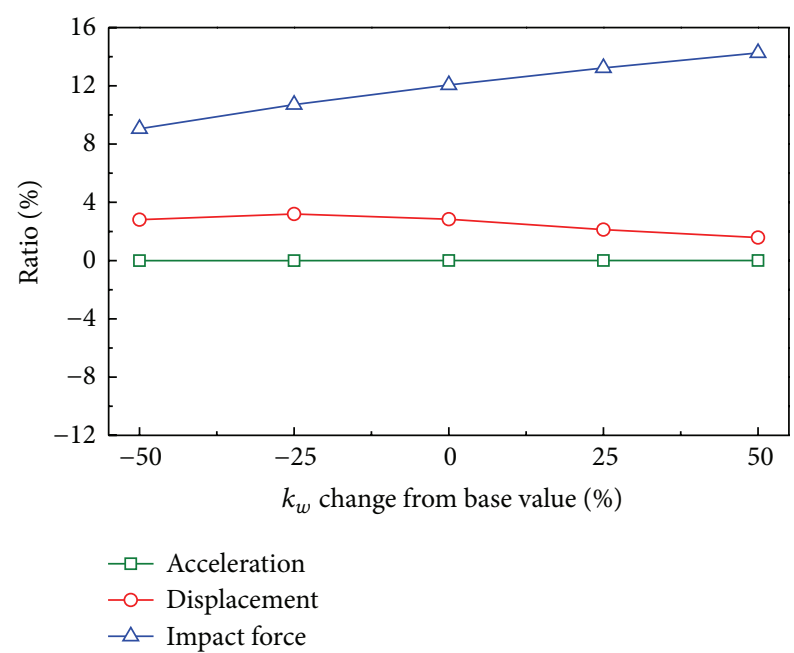

FIGURE 11: Effect of changing moat wall spring stiffness on structural response.

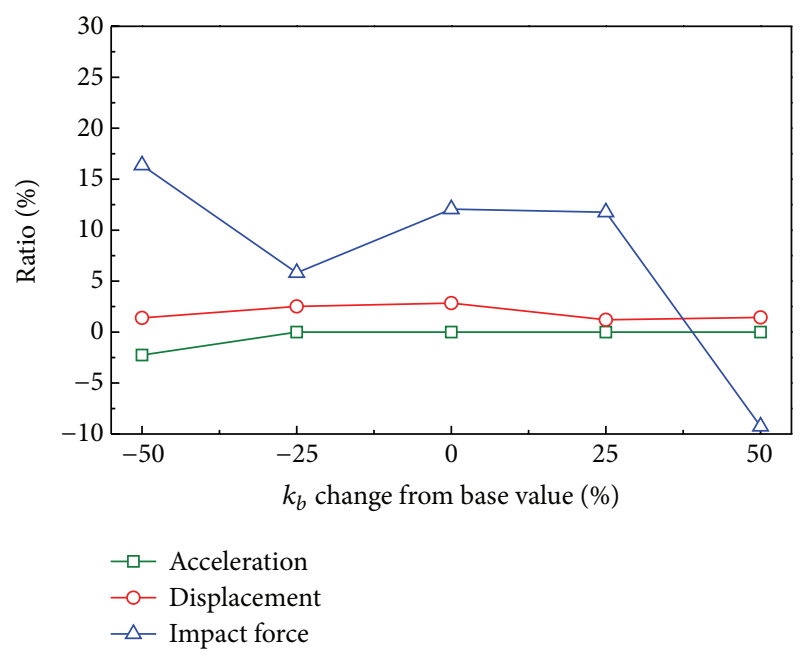

FIGURE 12: Effect of changing isolation layer spring stiffness on structural response. force using ELIM is not recommended if spring stiffness of isolated structure is varied largely. The maximum change in all structure response is less than $15 \%$ due to $50 \%$ change in the three parameters. The sensitivity analysis shows that ELIM is a reliable model considering uncertainty in assigning parameter. However, the drawback of ELIM is that isolated structure model parameters should be taken into account for ELIM to obtain more accurate simulation results.

\section{Conclusions}

In the Hertz contact model with nonlinear damping, the expression has been validated by shaking table test, but it cannot be directly used in the commercial software packages. To simplify it, an approximate formula of ELIM is theoretically derived based on equating energy dissipation and maximum collision compression deformation of isolated structure using the Hertz-damp model and Kevin-Voigt model in the process of collision. By comparing numerical analysis and experimental results of dropping balls, the correctness of formula (17) has been verified. This model can be used into commercial software packages by inputting linear impact stiffness and damping. As it is easy for engineers to calculate linear impact stiffness and damping of ELIM based on Hertzdamp model, ELIM can be directly adopted in engineering practice. ELIM is recommended to be used in actual projects due to its inexpensive computational overhead.

In addition, ELIM can be used to predict impact response and capture impact behavior of base-isolated structure pounding against moat wall subjected to near-fault pulselike earthquakes. The numerical simulations indicate that the acceleration and displacement responses of isolated structure and surrounding wall can be captured by comparing Hertzdamp and ELIM. It is beneficial for engineers to design a reasonable base-isolated structure pounding against moat wall. Sensitivity analysis conducted shows that the maximum change in structure response is less than $16 \%$ due to a $50 \%$ change in impact model parameters. These studies demonstrate that ELIM can provide reasonable results considering uncertainty in assigning model parameters. Therefore, reliable results of pounding simulation in structural engineering can be obtained from ELIM.

\section{Notations}

$\begin{array}{ll}m_{1}, m_{2}: & \text { Masses of impact bodies } \\ v_{1}, v_{2}: & \text { The velocities before impact } \\ k_{h}, c_{h}: & \begin{array}{l}\text { The nonlinear impact spring stiffness } \\ \text { and damping }\end{array} \\ g_{p}: & \text { Gap width } \\ R_{1}, R_{2}: & \text { Radii of two isotropic spheres } \\ \lambda_{1}, \lambda_{2}: & \text { Material parameters } \\ v_{i} \text { and } E_{i}: \begin{array}{l}\text { Poisson's ratio and modulus of elasticity } \\ \text { of sphere } i, \text { respectively }\end{array} \\ m_{i}: & \text { Colliding mass } \\ \rho_{i}: & \text { The density of concrete } \\ V: & \text { A common velocity of the two bodies } \\ \delta_{\max }: & \text { Maximum penetration. }\end{array}$




\section{Conflict of Interests}

The authors declare that there is no conflict of interests regarding the publication of this paper.

\section{Acknowledgment}

The authors gratefully acknowledge the financial support of National Natural Science Foundation of China nos. 51278291 and 51308331.

\section{References}

[1] G. L. Cole, R. P. Dhakal, and F. M. Turner, "Building pounding damage observed in the 2011 Christchurch earthquake," Earthquake Engineering and Structural Dynamics, vol. 41, no. 5, pp. 893-913, 2012.

[2] S. Nagarajaiah and X. Sun, "Base-isolated FCC building: impact response in Northridge Earthquake," Journal of Structural Engineering, vol. 127, no. 9, pp. 1063-1075, 2001.

[3] V. A. Matsagar and R. S. Jangid, "Seismic response of baseisolated structures during impact with adjacent structures," Engineering Structures, vol. 25, no. 10, pp. 1311-1323, 2003.

[4] V. A. Matsagar and R. S. Jangid, "Impact response of torsionally coupled base-isolated structures," Journal of Vibration and Control, vol. 16, no. 11, pp. 1623-1649, 2010.

[5] P. Komodromos, P. C. Polycarpou, L. Papaloizou, and M. C. Phocas, "Response of seismically isolated buildings considering poundings," Earthquake Engineering \& Structural Dynamics, vol. 36, no. 12, pp. 1605-1622, 2007.

[6] P. Komodromos, "Simulation of the earthquake-induced pounding of seismically isolated buildings," Computers and Structures, vol. 86, no. 7-8, pp. 618-626, 2008.

[7] V. K. Agarwal, J. M. Niedzwecki, and J. W. van de Lindt, "Earthquake induced pounding in friction varying base isolated buildings," Engineering Structures, vol. 29, no. 11, pp. 2825-2832, 2007.

[8] P. C. Polycarpou and P. Komodromos, "Earthquake-induced poundings of a seismically isolated building with adjacent structures," Engineering Structures, vol. 32, no. 7, pp. 1937-1951, 2010.

[9] P. C. Polycarpou and P. Komodromos, "On poundings of a seismically isolated building with adjacent structures during strong earthquakes," Earthquake Engineering and Structural Dynamics, vol. 39, no. 8, pp. 933-940, 2010.

[10] D. R. Pant and A. C. Wijeyewickrema, "Structural performance of a base-isolated reinforced concrete building subjected to seismic pounding," Earthquake Engineering and Structural Dynamics, vol. 41, no. 12, pp. 1709-1716, 2012.

[11] A. Masroor and G. Mosqueda, "Impact model for simulation of base isolated buildings impacting flexible moat walls," Earthquake Engineering and Structural Dynamics, vol. 42, no. 3, pp. 357-376, 2013.

[12] A. Moustafa and S. Mahmoud, "Damage assessment of adjacent buildings under earthquake loads," Engineering Structures, vol. 61, pp. 153-165, 2014.

[13] S. Muthukumar, A contact element approach with hysteresis damping for the analysis and design of pounding in bridges [Ph.D. thesis], Georgia Institute of Technology, 2003.
[14] R. Jankowski, "Non-linear viscoelastic modelling of earthquake-induced structural pounding," Earthquake Engineering and Structural Dynamics, vol. 34, no. 6, pp. 595-611, 2005.

[15] R. DesRoches and S. Muthukumar, "Effect of pounding and restrainers on seismic response of multiple-frame bridges," Journal of Structural Engineering, vol. 128, no. 7, pp. 860-869, 2002.

[16] A. Ruangrassamee and K. Kawashima, "Relative displacement response spectra with pounding effect," Earthquake Engineering and Structural Dynamics, vol. 30, no. 10, pp. 1511-1538, 2001.

[17] W. Goldsmith, Impact: The Theory and Physical Behavior of Colliding Solids, Dover, New York, NY, USA, 2001.

[18] K. T. Chau, X. X. Wei, X. Guo, and C. Y. Shen, "Experimental and theoretical simulations of seismic poundings between two adjacent structures," Earthquake Engineering \& Structural Dynamics, vol. 32, no. 4, pp. 537-554, 2003.

[19] P. C. Polycarpou, P. Komodromos, and A. C. Polycarpou, "A nonlinear impact model for simulating the use of rubber shock absorbers for mitigating the effects of structural pounding during earthquakes," Earthquake Engineering and Structural Dynamics, vol. 42, no. 1, pp. 81-100, 2013.

[20] D. R. Pant and A. C. Wijeyewickrema, "Performance of base-isolated reinforced concrete buildings under bidirectional seismic excitation considering pounding with retaining walls including friction effects," Earthquake Engineering \& Structural Dynamics, vol. 43, no. 10, pp. 1521-1541, 2014.

[21] S. Khatiwada, N. Chouw, and J. W. Butterworth, "A generic structural pounding model using numerically exact displacement proportional damping," Engineering Structures, vol. 62-63, pp. 33-41, 2014.

[22] M. Xu, Y. Wang, X. Jin, and Z. Huang, "Random vibration with inelastic impact: equivalent nonlinearization technique," Journal of Sound and Vibration, vol. 333, no. 1, pp. 189-199, 2014.

[23] S. E. Abdel Raheem, "Mitigation measures for earthquake induced pounding effects on seismic performance of adjacent buildings," Bulletin of Earthquake Engineering, vol. 12, no. 4, pp. $1-20,2014$.

[24] A. Masroor and G. Mosqueda, "Experimental simulation of base-isolated buildings pounding against moat wall and effects on superstructure response," Earthquake Engineering and Structural Dynamics, vol. 41, no. 14, pp. 2093-2109, 2012.

[25] R. Jankowski, "Analytical expression between the impact damping ratio and the coefficient of restitution in the non-linear viscoelastic model of structural pounding," Earthquake Engineering and Structural Dynamics, vol. 35, no. 4, pp. 517-524, 2006.

[26] S. Muthukumar and R. DesRoches, "A Hertz contact model with non-linear damping for pounding simulation," Earthquake Engineering and Structural Dynamics, vol. 35, no. 7, pp. 811-828, 2006.

[27] K. Ye, L. Li, and H. Zhu, "Modified kelvin pounding analytical model," Engineering Mechanics, vol. 12, no. 26, pp. 245-248, 2009 (Chinese).

[28] K. Ye, L. Li, and H. Zhu, "A note on the Hertz contact model with nonlinear damping for pounding simulation," Earthquake Engineering and Structural Dynamics, vol. 38, no. 9, pp. 1135$1142,2009$.

[29] R. Jankowski, "Comparison of numerical models of impact force for simulation of earthquake-induced structural pounding," in Computational Science-ICCS 2008, vol. 5101 of Lecture Notes in Computer Science, pp. 710-717, Springer, Berlin, Germany, 2008. 

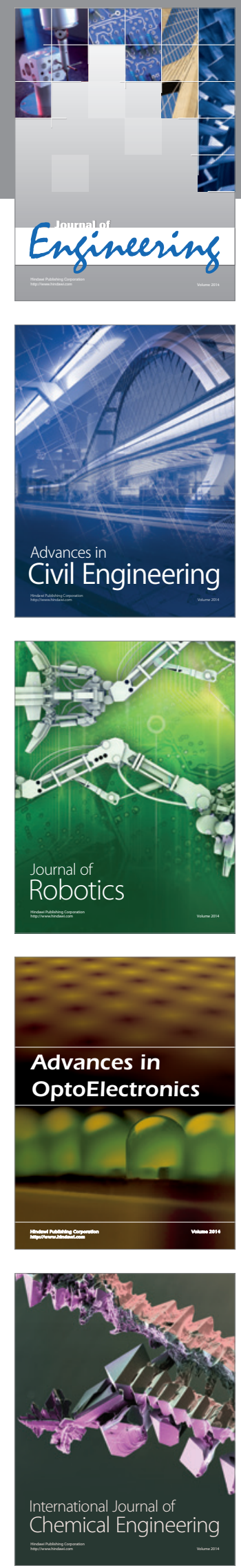

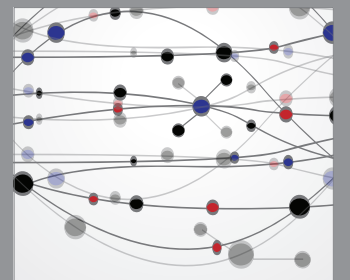

The Scientific World Journal
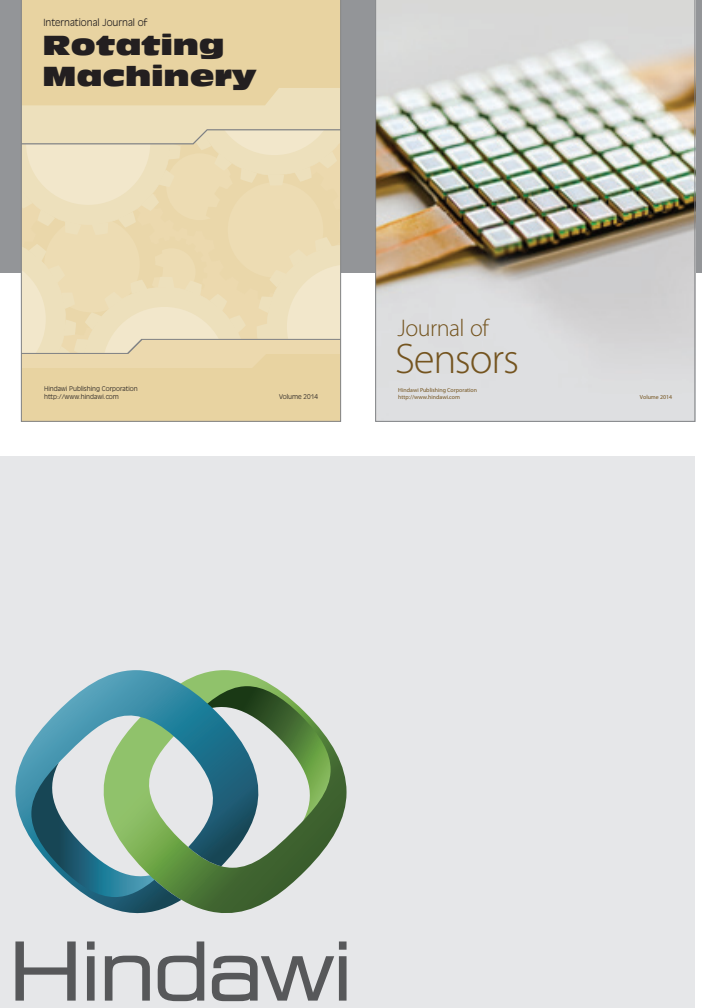

Submit your manuscripts at http://www.hindawi.com
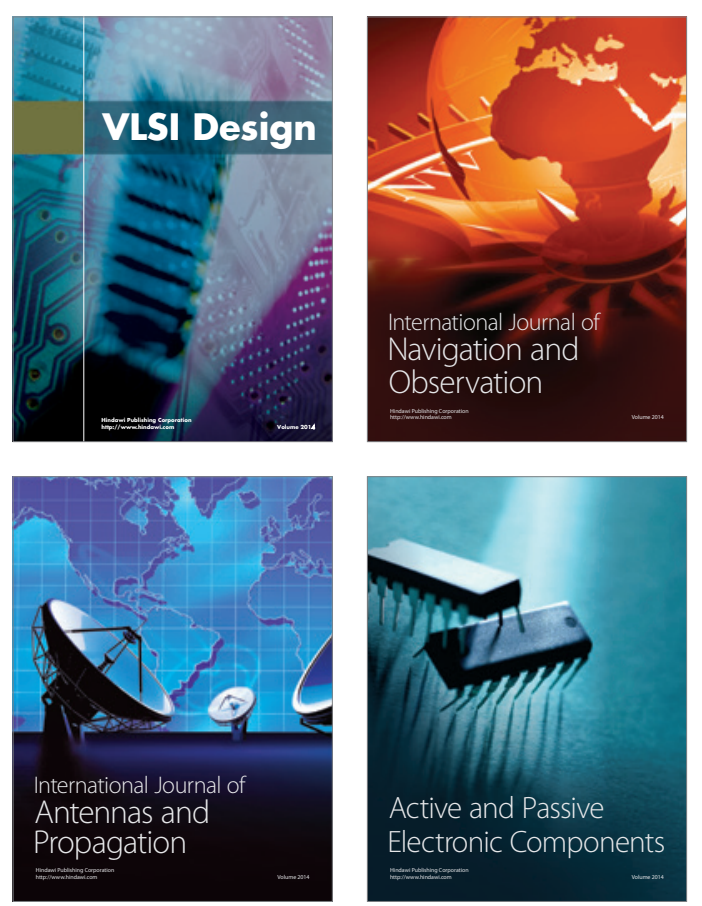
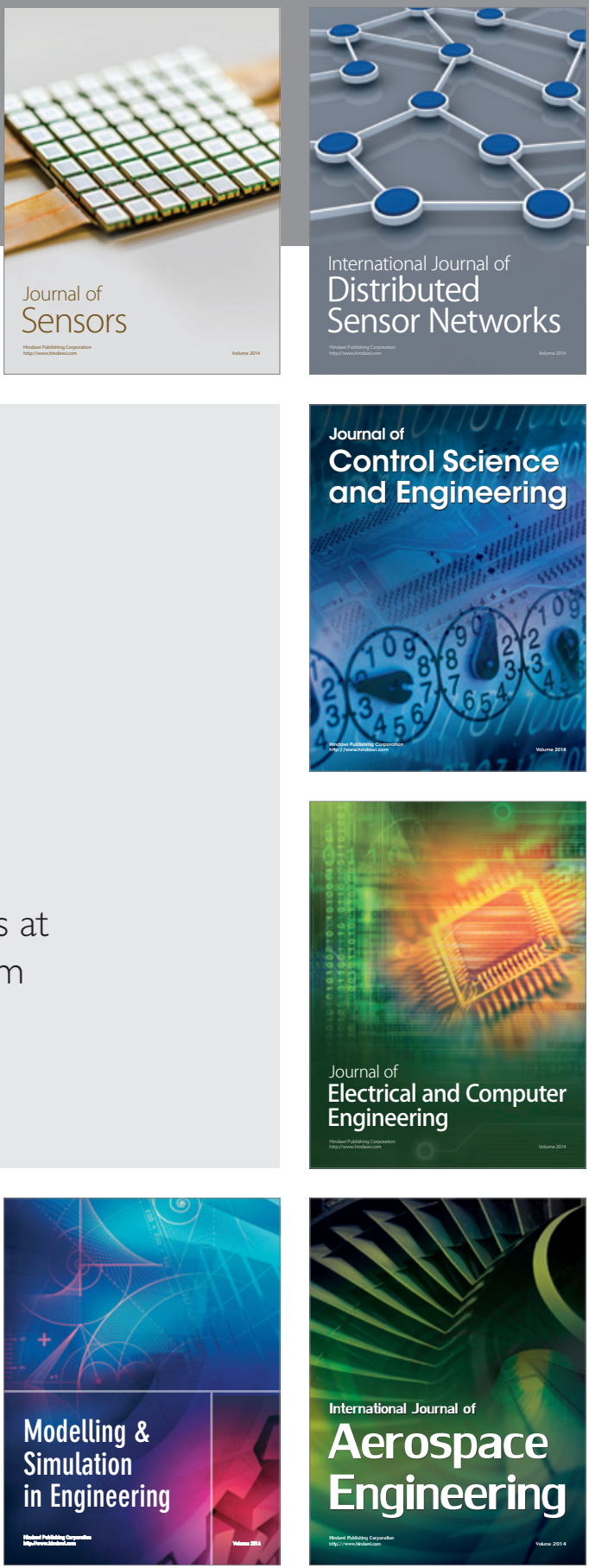

Journal of

Control Science

and Engineering
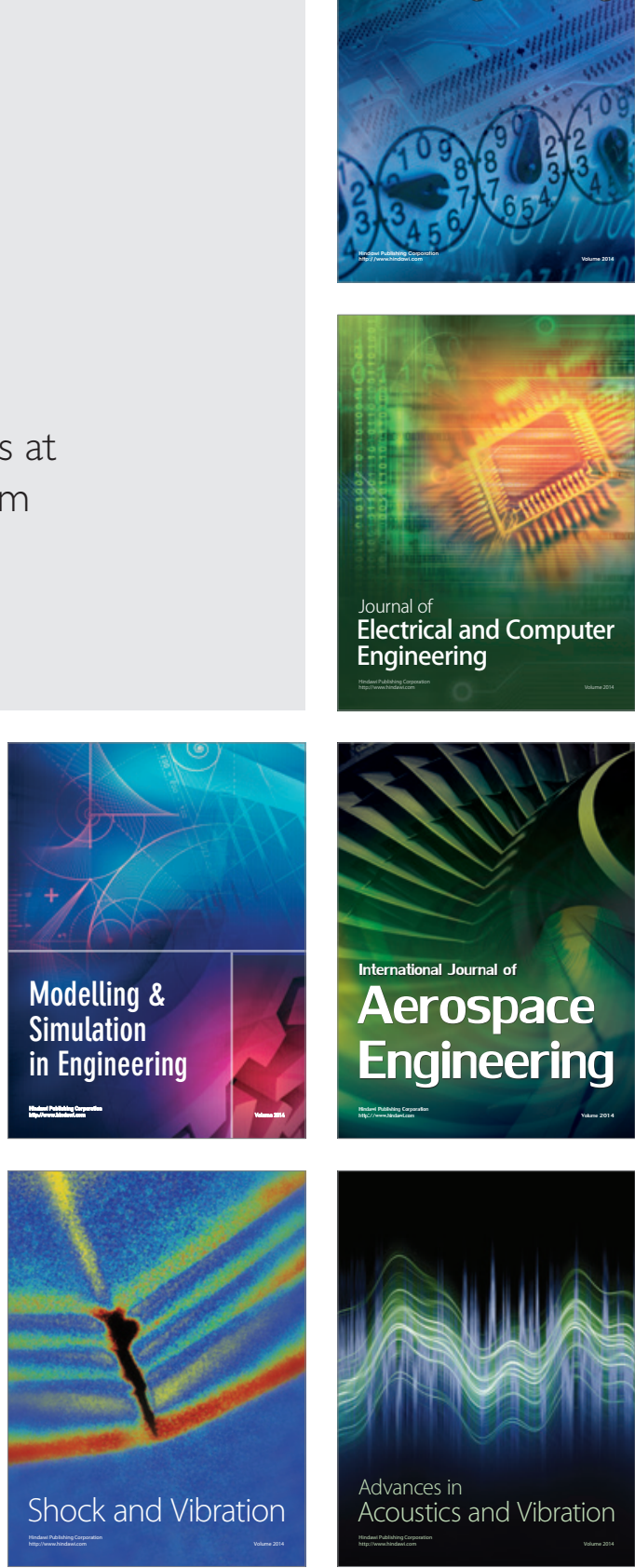